\title{
HIGH TEMPERATURE PROPERTIES OF A SINGLE CRYSTAL SUPERALLOY PWA1484 DIRECTLY RECYCLED AFTER TURBINE BLADE USE
}

\author{
Satoshi Utada ${ }^{1,2}$, Yuichiro Joh ${ }^{1,2}$, Makoto Osawa ${ }^{2}$, Tadaharu Yokokawa ${ }^{2}$, Toshiharu Kobayashi², \\ Kyoko Kawagishi ${ }^{2}$, Shinsuke Suzuki ${ }^{1}$, and Hiroshi Harada ${ }^{1,2}$ \\ ${ }^{1}$ Waseda University, Department of Applied Mechanics and Aerospace Engineering; 3-4-1 Okubo, Shinjuku-ku, Tokyo 169-8555, Japan \\ ${ }^{2}$ National Institute for Materials Science; 1-2-1 Sengen, Tsukuba, Ibaraki 305-0047, Japan
}

Keywords: Ni-base superalloy, Recycle, Creep, Oxidation, PWA1484, Desulfurization, Refining, Manufacturing

\begin{abstract}
To achieve drastic cost reduction and stable supply of Ni-base single crystal superalloy turbine blades, we proposed direct recycle method that includes collecting of the components, remelting and refining in the $\mathrm{CaO}$ crucible, adjusting composition using the "Counter Alloying Method", and recasting into single crystals. In this study, used and scrapped Ni-base single crystal superalloy PWA1484 turbine blades were directly recycled and the properties of the recycled materials were evaluated by performing high temperature tests such as creep, cyclic oxidation, and high cycle fatigue. The recycled material showed properties equal to or better than the genuine ingot material.
\end{abstract}

\section{Introduction}

Ni-base single crystal superalloys have superior high-temperature properties and they are very suitable for high pressure turbine components of jet engines and industrial gas turbines that require a high heat resistance. In these combustion engines, increasing the turbine inlet temperature and reducing the cooling air are desired for better specific fuel consumption. Therefore, the heat resistance of the Ni-base single crystal superalloys have been rising continuously [1]. However, the advanced $4^{\text {th }}[2,3], 5^{\text {th }}[4]$, and $6^{\text {th }}$ [5] generation Ni-base single crystal superalloys have not been used widely at the moment despite their performance. This is because of the higher alloy cost due to the higher content of refractory metal in the alloys, such as W, Ta, Re, and Ru. Recycling of scrapped turbine blades is a promising way of cost reduction, but presently it is not well established. Only expensive elements are extracted and used as alloying additions $[6,7]$ but the amount is limited.

In order to increase the recycling rate of the scrapped Ni-base single crystal superalloy turbine blades, a direct recycle method has been proposed by Kobayashi et al. [8]. This direct recycle method includes these processes: collecting of scrapped turbine blades, remelting of the blades, and recasting of the turbine components and/or alloy ingot. The major feature of the method is that scrapped blades are just remelted instead of refined back to individual elements. The method enables a drastic reduction in the lifetime costs of Ni-base single crystal superalloys. It is also effective for secure reuse and stabilizing the supply of rare elements. Kobayashi et al. [8] remelted scrapped turbine blades made of $2^{\text {nd }}$ generation Ni-base single crystal superalloy PWA1484 with thermal barrier coatings (TBC) and cast as a recycled material. The creep test results of the material showed that the composition change through the recycling process degrades its creep strength at $1100{ }^{\circ} \mathrm{C} / 137 \mathrm{MPa}$ to about half of that of the genuine ingot material.
Ni-base single crystal superalloy turbine blades typically have a TBC consisting of a metallic bond coating and ceramic top coating. The metallic bond coatings have several types, Ni-Co-Cr-Al-Y, $\mathrm{Co}-\mathrm{Ni}-\mathrm{Cr}-\mathrm{Al}-\mathrm{Y}$, and $\mathrm{Ni}-\mathrm{Al}$, and they improve adhesiveness of the ceramic top coating. Under high temperature environment, interdiffusion of the constituent elements between the metallic bond coating and the substrate occurs. The bond coating layer, the interdiffusion layer, and the substrate consist of rare metal elements. It is desired to retain these layers for recycling instead of removing them. However, as was already mentioned, recycling with these layers may change the composition of the recycled alloys, which could cause property degradation. To solve this problem, the alloy composition must be adjusted during the recycling process.

Kobayashi et al. [8] pointed out that sulfur, typical contamination of used turbine blades from the environment, could cause property degradation. Joh et al. [9] revealed that as sulfur content in Ni-base single crystal superalloy increases, the creep strength decreases. Sarioglu et al. [10] performed cyclic oxidation tests of PWA1484 with various sulfur content from $<0.1 \mathrm{ppm}$ to $45 \mathrm{ppm}$. Doping $8 \mathrm{ppm}$ sulfur to PWA1484 resulted in visible reduction of oxidation resistance [10]. Negative effects of sulfur contamination are unacceptable to obtain practical properties of directly recycled material. To establish a direct recycle method, desulfurization of a recycled material plays an important role. Sarioglu et al. [10] demonstrated that the sulfur content can be reduced to less than 0.1 ppm through hydrogen annealing. In spite of the effectiveness, the method requires an extra process to the production and is too expensive to apply to commercial production.

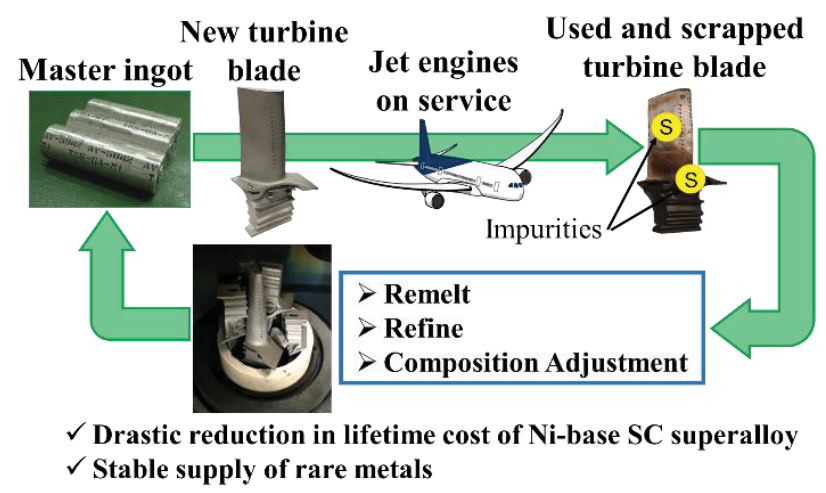

Figure 1. Schematic diagram of direct recycle of turbine blades. This process enables high recycling rate, low recycling cost, and low environmental pollution. 
In order to solve the problems mentioned, we proposed a direct recycle method that includes a combination of the Counter Alloying (CA) Method, or composition adjustment method, and refining method using a $\mathrm{CaO}$ crucible. The $\mathrm{CA}$ method adjusts composition during the remelting process by adding composition adjustment additives. The $\mathrm{CaO}$ crucible is applied due to its track record of refining in steel manufacturing process and its desulfurization effect [11].

We have already performed some experiments to demonstrate our proposed recycling method [12]. The sulfur content of the recycled material made from scrapped turbine blades was successfully lowered and its creep strength was recovered to the level of material that was cast from genuine ingot. However, other high temperature properties such as oxidation resistance and high cycle fatigue (HCF) strength have not been evaluated. Detailed analysis of microstructure is also needed.

The purpose of this study was to demonstrate full recovery of the high temperature properties of the recycled material and to discuss reasons of its recovery. Scrapped turbine blades were recycled directly at the $2 \mathrm{~kg}$ level by the proposed method and a total of 4 kinds of materials were prepared. High temperature property tests such as creep tests and cyclic oxidation tests were performed as a typical evaluation index of turbine blade materials. Also, high temperature HCF tests were performed. Properties of recycled materials were verified in several perspectives; major composition variation, impurity content, and microstructure analysis.

\section{Test Material Preparation}

Genuine Material

To compare with recycled materials, single crystal rods of the "genuine material" were cast from PWA1484 genuine ingot. About $2 \mathrm{~kg}$ of genuine ingot was prepared and was melted by induction melting in a vacuum directional solidification furnace under pressure lower than $6 \times 10^{-2} \mathrm{~Pa}$. After melting, the temperature of the melt was raised to $1600{ }^{\circ} \mathrm{C}$ in an $\mathrm{Al}_{2} \mathrm{O}_{3}$ crucible and a single crystal bar mold was kept at $1500{ }^{\circ} \mathrm{C}$. The melt was poured and top filled into the single crystal bar mold with a ceramic filter on the mold sprue. The melt was unidirectionally solidified by withdrawing the mold from the heated zone at a speed of $200 \mathrm{~mm} / \mathrm{h}$. The cast bars were solution heat treated at $1315^{\circ} \mathrm{C}$ for $4 \mathrm{~h}$, followed by a heat treatment at $1080{ }^{\circ} \mathrm{C}$ for $4 \mathrm{~h}$, and secondary aging at $704{ }^{\circ} \mathrm{C}$ for $24 \mathrm{~h}$. After heat treatment, chemical composition analyses (methods are shown in Table I) were conducted.

Raw Material Processed from Scrapped Turbine Blades The scrapped PWA1484 high pressure turbine blades were sandblasted and cut to that they could be used as "raw material" for the recycling. The scrapped blades had a metallic bond coating over the substrate and ceramic coating on top. Only the ceramic top coating was removed by sandblasting so that the elements in the metallic bond coating could be included in the raw material.
After this process, all blades were cut into half so that they could be set in a crucible as raw materials. Unless otherwise noted, "raw material" will be the scrapped turbine blade that was sandblasted and cut.

Simple Recycle Material

About $2 \mathrm{~kg}$ of the raw materials were cast into single crystal bars, heat treated, and then the composition was analyzed under the same conditions as genuine material. It will be defined as "simple recycle material"

\section{Composition Adjusted Recycle Material "CA Material"}

In the casting process of "CA material", the additives were added to the melt of scrapped turbine blades in the furnace to obtain the same mixed composition as genuine material and then the melt was cast into single crystal bars. Casting, heat treating, and the composition analysis conditions of CA material were the same as the genuine material.

The composition of the additives was decided by the estimation of the following. First, the composition of the metallic bond coating was quantitatively analyzed using electron probe microanalysis (EPMA) to identify the specified composition. To determine from published information, PWA1365-1 [13] was assumed to be the specified composition of the analyzed coating and the average composition of PWA1365-1 was used for the estimation. The chemical composition of scrapped turbine blade's substrate was assumed to be the same as the genuine material. Then, the mass ratio of the metallic bond coating to the substrate was estimated by assuming the thickness and density of the coating as $0.1 \mathrm{~mm}$ and $7.24 \mathrm{~g} / \mathrm{cm}^{3}$ respectively. The composition of additives is shown in Table II.

\section{$\mathrm{CA}$ and $\mathrm{CaO}$ Refining Recycle Material " $\mathrm{CA}+\mathrm{CaO}$ "}

In this method, the chemical composition of the additives was finetuned by referring the result of chemical analysis of simple recycle material and CA material to obtain a closer composition to genuine material than CA material (Table II). The raw materials were placed in $\mathrm{CaO}$ crucible (purity $>99.9 \%$ ) in the furnace and additives were added after melting of the raw materials. Total weight of melt was about $2 \mathrm{~kg}$. After the material was completely melted, the melt was kept in $\mathrm{CaO}$ crucible for 15 min for desulfurization. Casting, heat treating, and the composition analysis conditions were the same as the genuine material.

Table I. Analysis Methods for Chemical Compositions

\begin{tabular}{|l|c|}
\hline \multicolumn{1}{|c|}{ Analysis method } & Elements \\
\hline Inductively coupled plasma- & $\mathrm{Ni}, \mathrm{Co}, \mathrm{Cr}, \mathrm{Mo}, \mathrm{W}$, \\
optical emission spectrometry & $\mathrm{Al}, \mathrm{Ta}, \mathrm{Hf}, \mathrm{Re}, \mathrm{Zr}$, \\
(ICP-OES) & $\mathrm{Fe}, \mathrm{Si}, \mathrm{Ca}, \mathrm{P}, \mathrm{Y}$ \\
\hline Combustion-infrared absorption & $\mathrm{C}, \mathrm{S}$ \\
\hline Inert gas fusion-thermal conductivity & $\mathrm{N}$ \\
\hline
\end{tabular}

Table II. The Composition of the Adjustment Additives (wt.\%)

\begin{tabular}{|c|c|c|c|c|c|c|c|c|c|}
\hline & $\mathrm{Co}$ & $\mathrm{Cr}$ & $\mathrm{Mo}$ & $\mathrm{W}$ & $\mathrm{Al}$ & $\mathrm{Ta}$ & $\mathrm{Hf}$ & $\mathrm{Re}$ & $\mathrm{Ni}$ \\
\hline $\mathrm{CA}$ & 4.52 & 0.00 & 2.80 & 8.39 & 3.76 & 12.59 & 0.14 & 4.20 & Bal. \\
\hline $\mathrm{CA}+\mathrm{CaO}$ & 8.74 & 0.00 & 2.17 & 10.98 & 6.23 & 14.42 & 0.00 & 4.72 & Bal. \\
\hline
\end{tabular}




\section{High Temperature Property Tests}

Creep test specimens (diameter $4 \mathrm{~mm}$ and parallel portion length $20 \mathrm{~mm}$ ) and high-temperature HCF test specimens (diameter $3.5 \mathrm{~mm}$ and parallel portion length $9 \mathrm{~mm}$ ) were prepared from single crystal bars with a longitudinal axis within $6^{\circ}$ from the crystal orientation of $\langle 001\rangle$. The X-ray back-reflection Laue method was conducted to determine the crystal orientations. The creep tests were conducted under the condition of $137 \mathrm{MPa}$ at $1100{ }^{\circ} \mathrm{C}$. The cyclic oxidation tests were performed at $1100{ }^{\circ} \mathrm{C}$ for 1 hour up to 50 cycles in air. High temperature HCF tests were performed at $1000{ }^{\circ} \mathrm{C}$, stress ratio $R=0$, frequency of $60 \mathrm{~Hz}$, and stress of $300 \mathrm{MPa}$ accordance with ASTM E466. After these tests, the specimens were evaluated using scanning electron microscopy (SEM), EPMA, and energy dispersive X-ray spectrometry (EDS).

\section{Results and Discussions}

Chemical Composition Analysis

Table III shows the analyzed composition of the metallic bond coating by the EPMA quantitative analyses. The coating is presumed to be Ni-Co-Cr-Al-Y and its presumed specification is also shown in Table III [13]. The decreased composition of Co and $\mathrm{Cr}$ and large error might be due to the inter-diffusion of the metallic bond coating and the substrate.

Table IV shows the results of the chemical analyses of major elements for all materials. The specified composition of PWA1484 is also shown in Table IV [14]. The content of W, Ta, and Re in the simple recycle material decreased because of the dissolution of the coating material (Ni-Co-Cr-Al-Y). The major element compositions of $\mathrm{CA}$ material and $\mathrm{CA}+\mathrm{CaO}$ were adjusted by the CA method. However, the compositions are not completely equal to the genuine material since the coating of scrapped turbine blades slightly varies.

Figure 2 shows the results of the chemical analyses of sulfur, oxygen, and nitrogen. Compared with the materials melted in the $\mathrm{Al}_{2} \mathrm{O}_{3}$ crucible, the effects of refining (desulfurization, deoxidation, and denitrification) are confirmed in the material melted in $\mathrm{CaO}$ crucible: $\mathrm{CA}+\mathrm{CaO}$. It should be noted that the content of impurities in $\mathrm{CA}+\mathrm{CaO}$ successfully decreased to the same level of the genuine material.

Table $\mathrm{V}$ shows the content of impurities other than $\mathrm{S}, \mathrm{O}$, and $\mathrm{N}$. The recycled materials have a higher content of $\mathrm{C}, \mathrm{Fe}, \mathrm{Si}$ and $\mathrm{Zr}$ than the genuine material. Carbon, $\mathrm{Fe}$, and Si contaminations came from internal deposits left in the air cooling channels. Zirconium contamination is from residual yttria stabilized zirconia (YSZ) ceramic coating that was not sufficiently removed by sandblasting. A feature of $\mathrm{CA}+\mathrm{CaO}$ is the slight increase of $\mathrm{Ca}$ which suggests that $\mathrm{Ca}$ was generated and was dissolved into the melt during the disulfuric reaction.

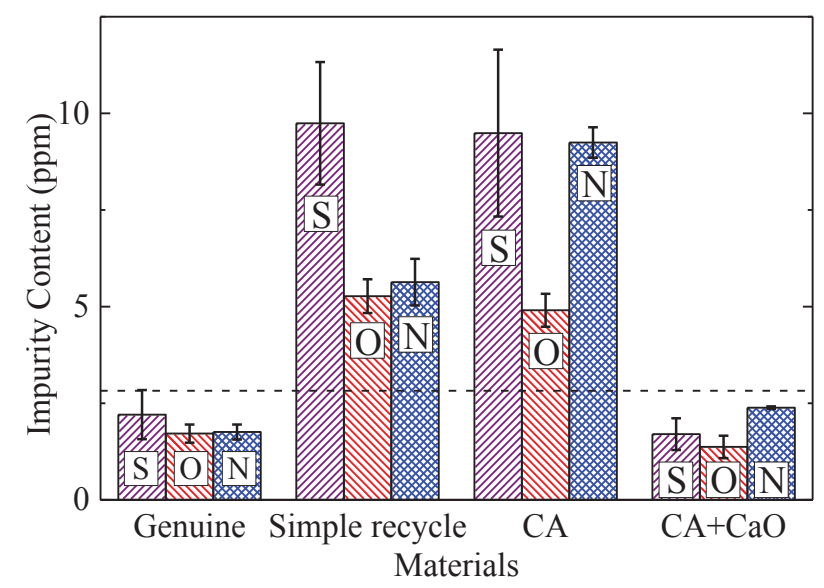

Figure 2. Content of major impurities such as sulfur, oxygen, and nitrogen for each material. Standard deviations of each impurity content are shown as error bars. $\mathrm{CA}+\mathrm{CaO}$ was successfully refined and the content of impurities decreased to the same level of the genuine material.

Table III. Analyzed Composition of the Metallic Coating (wt.\%)

\begin{tabular}{|c|c|c|c|c|c|}
\hline & $\mathrm{Ni}$ & $\mathrm{Co}$ & $\mathrm{Cr}$ & $\mathrm{Al}$ & $\mathrm{Y}$ \\
\hline PWA1365-1 spec. [13] & $\mathrm{Bal}$. & $18.0-28.0$ & $13.0-21.0$ & $10.0-15.0$ & $0.1-0.8$ \\
\hline Analysis average \pm error & $57.8 \pm 3.5$ & $18.0 \pm 2.8$ & $10.8 \pm 3.3$ & $13.1 \pm 2.6$ & $0.4 \pm 0.3$ \\
\hline
\end{tabular}

Table IV. The Composition of Major Elements in the Materials (wt.\%)

\begin{tabular}{|c|c|c|c|c|c|c|c|c|c|}
\hline & Co & Cr & Mo & W & Al & Ta & Hf & Re & Ni \\
\hline PWA1484 spec.[14] & 10.0 & 5.0 & 2.0 & 6.0 & 5.6 & 8.7 & 0.1 & 3.0 & Bal. \\
\hline Genuine & 9.58 & 4.91 & 1.88 & 5.93 & 5.65 & 8.72 & 0.09 & 3.05 & Bal. \\
\hline Simple recycle & 9.85 & 5.07 & 1.88 & $5.81 \downarrow$ & 5.58 & $8.43 \downarrow$ & 0.10 & 2.96 & Bal. \\
\hline CA & 9.85 & 4.92 & 1.91 & 5.96 & $5.45 \downarrow$ & 8.56 & 0.11 & 3.02 & Bal. \\
\hline CA+CaO & 9.64 & 4.41 & 1.93 & 6.21 & $5.42 \downarrow$ & 8.88 & 0.09 & 3.16 & Bal. \\
\hline
\end{tabular}

Table V. Content of Other Impurities (ppm)

\begin{tabular}{|c|c|c|c|c|c|c|c|}
\hline & $\mathrm{C}$ & $\mathrm{Zr}$ & $\mathrm{Fe}$ & $\mathrm{Si}$ & $\mathrm{Ca}$ & $\mathrm{P}$ & $\mathrm{Y}$ \\
\hline Genuine & 40 & 17 & 130 & 582 & 3.2 & 9 & 6.6 \\
\hline Simple recycle & 145 & 60 & 399 & 898 & 3.3 & 3 & 3.3 \\
\hline $\mathrm{CA}$ & 101 & 50 & 371 & 767 & 3.3 & 22 & 7.4 \\
\hline $\mathrm{CA}+\mathrm{CaO}$ & 101 & 78 & 386 & 710 & 5.5 & 36 & 6.4 \\
\hline
\end{tabular}




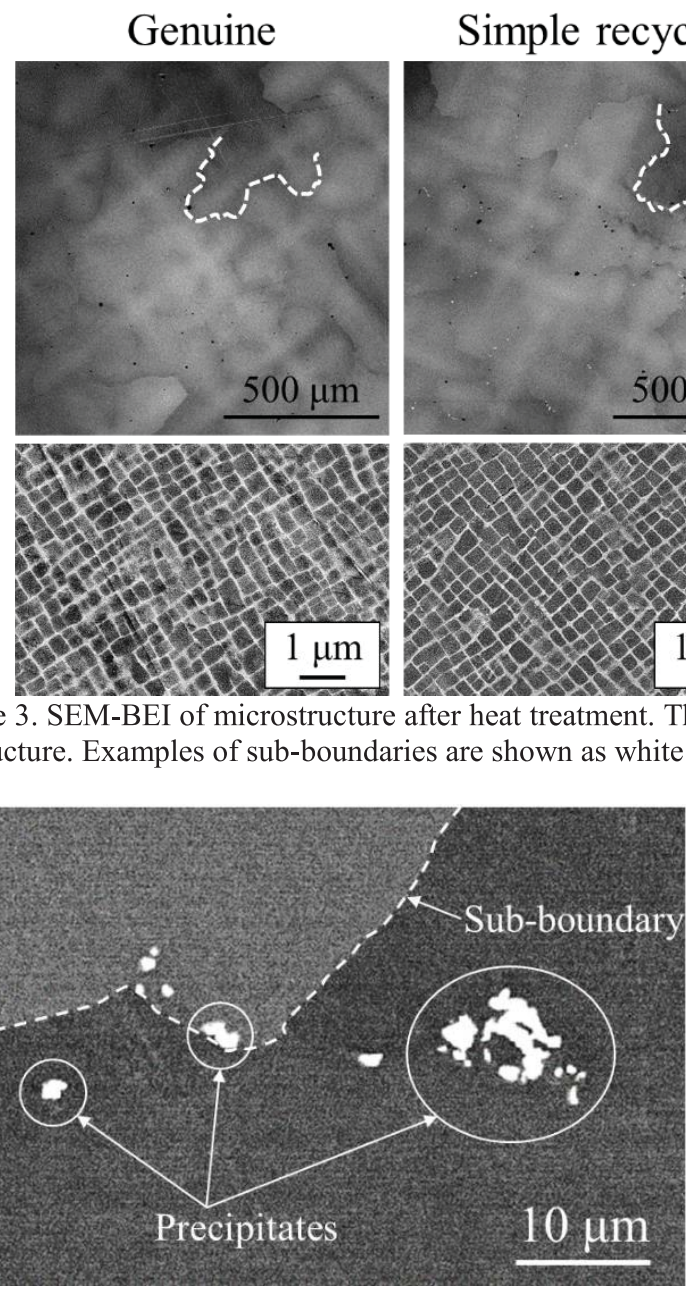

Figure 4. The precipitates in $\mathrm{CA}+\mathrm{CaO}$ after heat treatment. The precipitates are often seen at and around the sub-boundaries of the recycled materials.

\section{Microstructure before Tests}

Figure 3 shows SEM-backscatter electron images (BEI) of all materials after heat treatment. The microstructures are similar to each other in both scales of dendrites and $\gamma-\gamma^{\prime}$ structure. All materials have visible difference in contrast other than the dendrites; examples are shown by white dashed lines in each figure. This strong contrast line means that the materials have subboundaries. However, the crystal orientation difference in a single specimen was within $2^{\circ}$, which hardly affected to the creep strength of the materials.

Small amount of precipitates are seen at and around the subboundaries of the recycled materials (Figure 4). The result of the EPMA spot quantitative analysis shows that the precipitates are carbides and are mainly composed of $\mathrm{TaC}$ and HfC. These are typical precipitates in carbon containing Ni-base superalloys [15]. Liu et al. reported that carbides precipitate in the interdendritic region of the Ni-base single crystal superalloy with $150 \mathrm{ppm}$ carbon content [16]. The carbide content and precipitation region of carbides in the recycled materials of our study are similar to those of past research [16]. No other microstructural difference is seen in all materials.

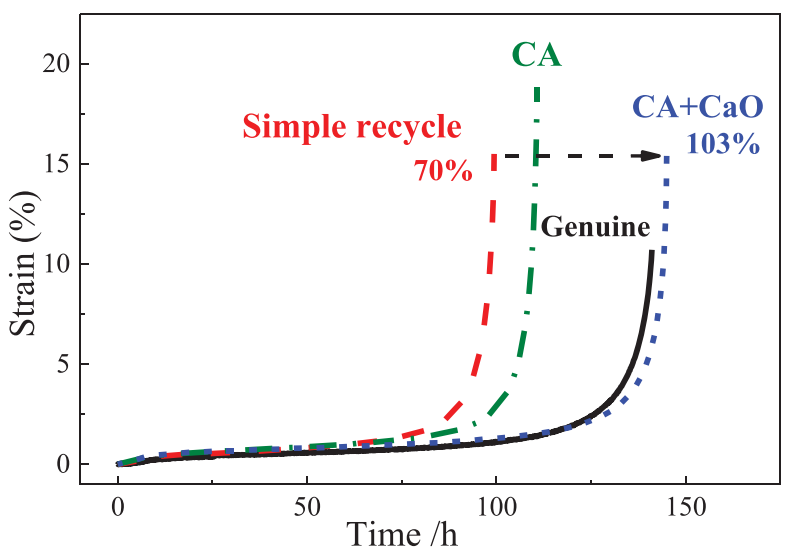

Figure 5. The results of creep test at $1100{ }^{\circ} \mathrm{C} / 137 \mathrm{MPa}$. The simple recycle material has $70 \%$ and $\mathrm{CA}+\mathrm{CaO}$ has $103 \%$ of the creep rupture life of the genuine material, respectively. Creep strength of $\mathrm{CA}+\mathrm{CaO}$ is recovered to the same level of the genuine material.

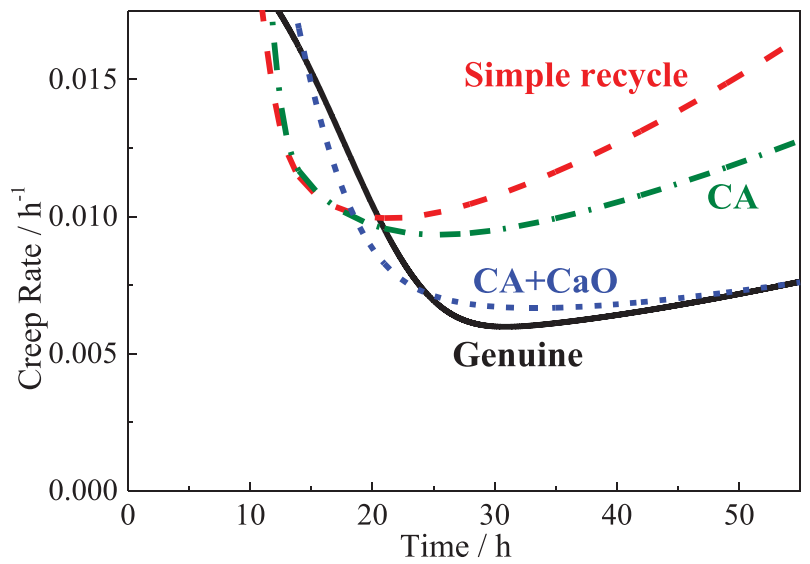

Figure 6. Creep rate curves derived from the results of the creep tests at $1100{ }^{\circ} \mathrm{C} / 137 \mathrm{MPa}$. The genuine material and $\mathrm{CA}+\mathrm{CaO}$ showed similar creep characteristic in terms of creep rate. 


\section{Creep Tests}

Figure 5 shows the results of $1100{ }^{\circ} \mathrm{C} / 137 \mathrm{MPa}$ creep tests. The simple recycle material, $\mathrm{CA}$ material, and $\mathrm{CA}+\mathrm{CaO}$ had $70 \%, 79 \%$, and $103 \%$ of the creep rupture life of the genuine material, respectively. Figure 6 shows the creep rate of the specimens derived from the results in Figure 5. In terms of both creep rupture life and creep rate, $\mathrm{CA}+\mathrm{CaO}$ has the equivalent characteristic compared to the genuine material.

Figure 7 shows SEM-BEI of all materials after creep rupture test. The raft structures of creep ruptured specimens are similar in all samples. However, the difference in the appearance and sites of precipitates in each sample were observed. Granular shaped carbides were observed in the interdendritic region of creep ruptured specimens of the recycled materials. Needle-shaped (or plate-like in actual shape) precipitates were observed in the dendritic region of the genuine material. The precipitates are topologically closed packed (TCP) phases which are typically found in 3 wt.\% Re containing $2^{\text {nd }}$ generation Ni-base single crystal superalloys [17]. In the recycled materials, TCP phases were observed but their cross section shapes are longer than TCP phases seen in the genuine material. It has to be noted that the precipitation amount of TCP phases in $\mathrm{CA}+\mathrm{CaO}$ is the smallest of the materials. Also, TCP phases in $\mathrm{CA}+\mathrm{CaO}$ are distributed widely instead of concentrating in dendrite cores.

Qualitative EDS maps of precipitates in $\mathrm{CA}+\mathrm{CaO}$ are shown in Figures 8 and 9. The white part of the granular precipitates can be determined as typical carbides because of the Ta and Hf content as mentioned before. Also, the darker parts of the granular precipitates were observed next to the white parts with enrichment of $\mathrm{W}, \mathrm{Re}, \mathrm{Y}$ and $\mathrm{S}$. The composition of major elements in the darker parts suggests that TCP phases co-exist with carbides in the recycled materials. Needle-shaped precipitates in $\mathrm{CA}+\mathrm{CaO}$ are distributed differently compared to other materials, but the enrichment of refractory elements suggests that the precipitates are TCP phases. Yttrium and $\mathrm{S}$ were detected in the needle-shaped precipitates as in the darker part of the granular precipitates.



Figure 7. SEM-BEI of microstructure after creep test. Large differences are not observed in terms of amount of precipitates between the genuine and the recycled materials.
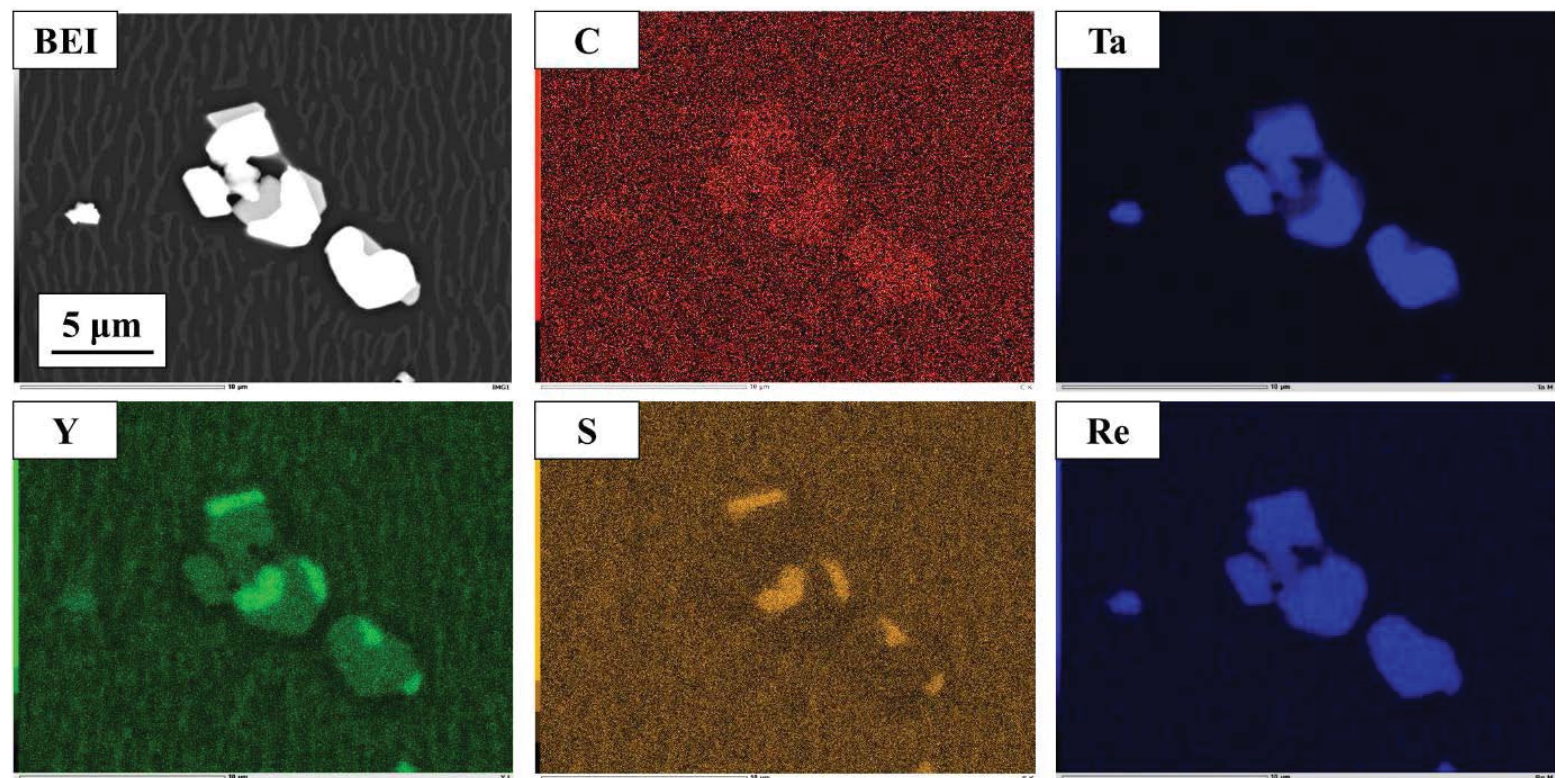

Figure 8. The result of EDS qualitative mapping of $\mathrm{CA}+\mathrm{CaO}$. The white parts in $\mathrm{BEI}$ of precipitates are carbides and the darker parts have TCP phase like composition plus Y and S. 

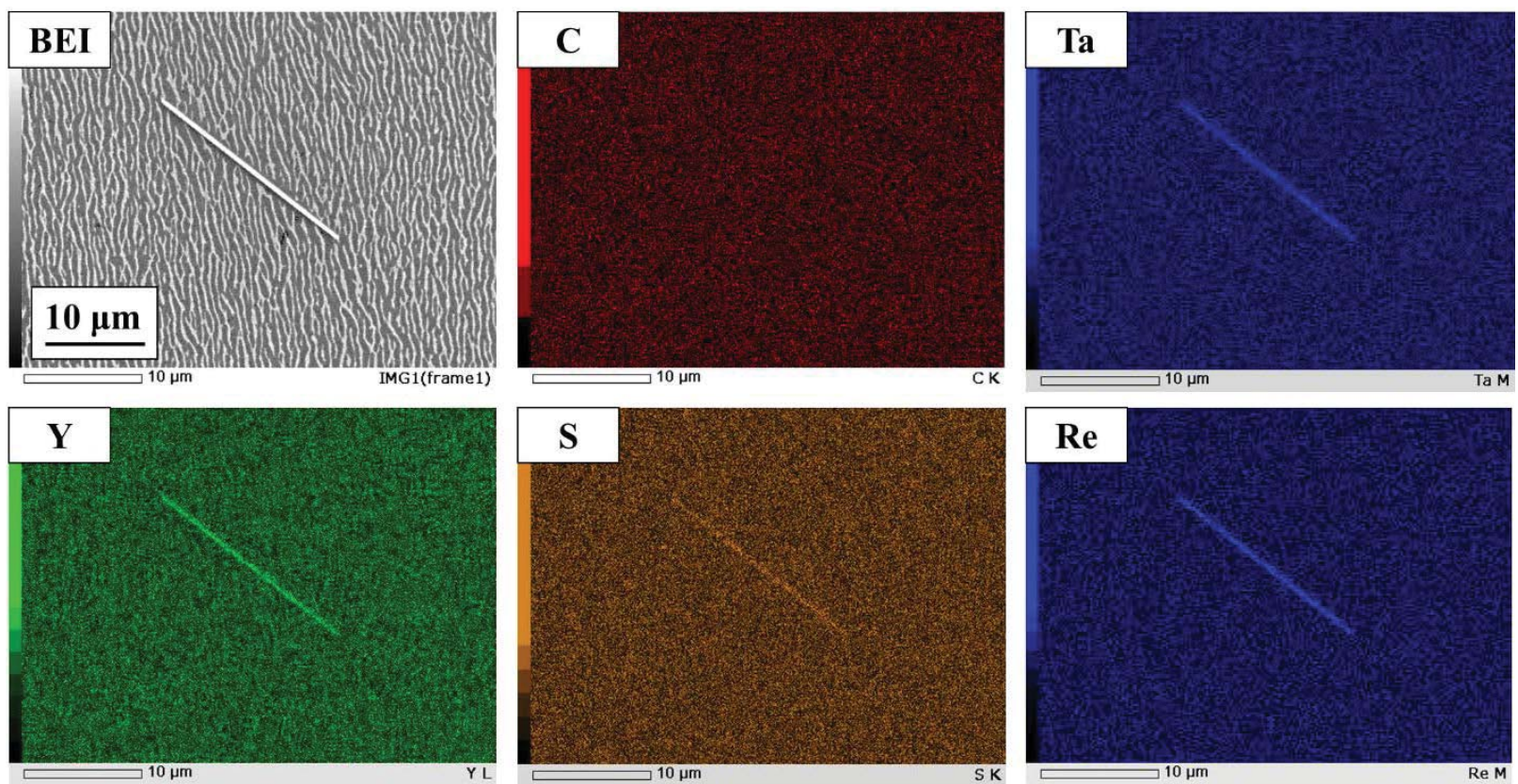

Figure 9. The result of EDS qualitative mapping of $\mathrm{CA}+\mathrm{CaO}$. Needle-shaped precipitates are TCP phase and it also contains $\mathrm{Y}$ and $\mathrm{S}$.

The TCP phases are mainly composed of refractory elements like $\mathrm{W}$ and Re which tend to solute in $\gamma$ phase. These elements tend to segregate heavily to dendrite core region. Therefore, TCP phases precipitate easier in primary dendrite core region in general. This trend can be seen in the genuine material, the simple recycled material, and $\mathrm{CA}$ material but not in $\mathrm{CA}+\mathrm{CaO}$. In $\mathrm{CA}+\mathrm{CaO}$, $\mathrm{TCP}$ phases tend to precipitate in edge of secondary dendritic arm, in other words intermediate area between brighter area (dendrite core) and darker area (interdendritic area). In Figure 8, granular precipitates with TCP phase-like compositions coexist with carbides. These facts suggest that carbides become precipitation sites of the TCP phases in the interdendritic region. This statement is supported by the result that the single TCP phase in Figure 9 has similar composition to the TCP phases that coexist with carbides.

As was shown in Figure 2, the simple recycled material and CA material have around $10 \mathrm{ppm}$ sulfur content. Creep strength degradation of Ni-base single crystal superalloy caused by around $20 \mathrm{ppm}$ sulfur content is reported by Joh et al. [9]. Therefore, the simple recycled material and CA material should show moderate property degradation. From the other point of view, the genuine material and $\mathrm{CaO}$ refined $\mathrm{CA}+\mathrm{CaO}$ should show no effect of sulfur contamination. However, according to Table IV, the major element compositions of the materials are different by a small amount. Now, this composition difference need to be considered.

Predicted creep rupture times of the materials are calculated from NIMS-ADP (Alloy Designing Program) [18] and are plotted on the horizontal axis of Figure 10. On the vertical axis, actual creep rupture times of the materials are plotted. When the alloy composition and the applied temperature and stress are input to the NIMS-ADP, the mechanical properties (ex: creep rupture life) are predicted by multiple regression analysis that references database. Absolute values of prediction and observation are different, but there is a good correlation to each other.

The creep rupture times of the recycled materials were evaluated by taking the result of the chemical composition analysis of the genuine material as a standard value (Table IV). The amount of W, $\mathrm{Ta}$, and $\mathrm{Re}$ in the simple recycled materials decreased due to the $\mathrm{Ni}, \mathrm{Co}, \mathrm{Cr}$ dissolution from metallic bond coating. Aluminum also decreased probably due to vaporization during remelting. This resulted in the simple recycled material having the shortest creep rupture life of all specimens. The CA material, composition adjusted, has the proper amount of $\mathrm{W}$ and $\mathrm{Re}$, but it has higher $\mathrm{Co}$ content and decreased amount of Al. The amount of solid-solution strengthening refractory elements $(\mathrm{W}, \mathrm{Ta}$, and $\mathrm{Re}$ ) and volume fraction of $\gamma^{\prime}$ phase (affected by Al content) greatly affect the creep strength of Ni-base single crystal superalloy [14]. To some extent, the creep strength degradation of the simple recycled material and CA material could be described by their compositions.

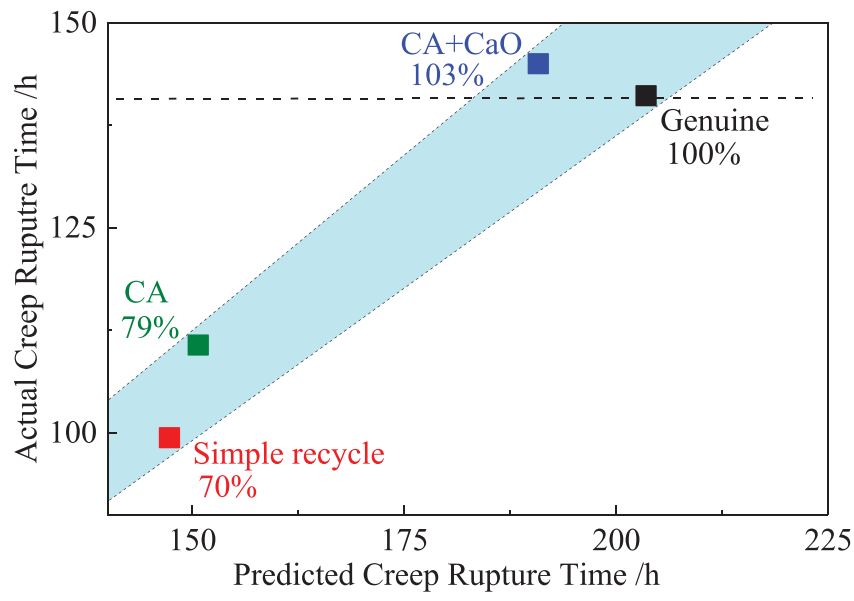

Figure 10. The results of creep test at $1100{ }^{\circ} \mathrm{C} / 137 \mathrm{MPa}$ and the relationship between predicted and actual creep rupture time are shown. The prediction and actual value showed good correlation. Chemical composition is the main factor of the creep strength. Control of its composition plays an important role in the direct recycle method. 
The creep properties of the genuine material and $\mathrm{CA}+\mathrm{CaO}$ are similar, but $\mathrm{CA}+\mathrm{CaO}$ has a slightly higher amount of refractory elements such as $\mathrm{W}$ and $\mathrm{Re}$, and slightly lower amount of $\mathrm{Al}$ content. Aluminum content decreased due to $\mathrm{CaO}-\mathrm{Al}_{2} \mathrm{O}_{3}$ forming disulfuric reaction between $\mathrm{Al}$ in melt and $\mathrm{CaO}$ crucible. The decreased amount of $\mathrm{Cr}$ does not affect creep strength much since $\mathrm{Cr}$ is for oxidation resistance and the solid solution strengthening effect of $\mathrm{Cr}$ is small. The increase in the amount of strengthening refractory elements and the decrease in $\gamma^{\prime}$ forming element cancelled out each other resulting in similar creep strength of the genuine material and $\mathrm{CA}+\mathrm{CaO}$.

From the comparison of the ADP prediction and experimental observation, the chemical composition is revealed to be the main factor resulting in the creep strength difference. At the same time, control of its composition is suggested to play an important role in the direct recycle method. Furthermore, the creep property of the recycled material was not affected by the content of other impurities resulting from the single recycling process; precipitates shown in Figure 7 have a negligible effect on the creep strength of the materials. This experiment was performed using a laboratory scale directionally solidification furnace. In the commercial scale ingot manufacturers, the composition of molten metal is qualitatively analyzed during melting process and more accurate composition adjustment is possible in an industrial operation.

\section{Cyclic Oxidation Tests}

Figure 11 shows results of the cyclic oxidation test. Weight gain means creation of oxidation scale and weight loss means the spallation of oxidation scale caused by thermal expansion coefficient difference between the substrate and the oxidation scale. The oxidation scale spalls off when the specimen thermally expands and contracts. The genuine material has the largest amount of negative weight change which means the worst oxidation resistance of the materials. The simple recycle material and CA material show better oxidation resistance than the genuine material but weight tends to decrease in both materials. $\mathrm{CA}+\mathrm{CaO}$ hardly spalled its oxidation scale and shows only positive weight change, having the best oxidation resistance of all.

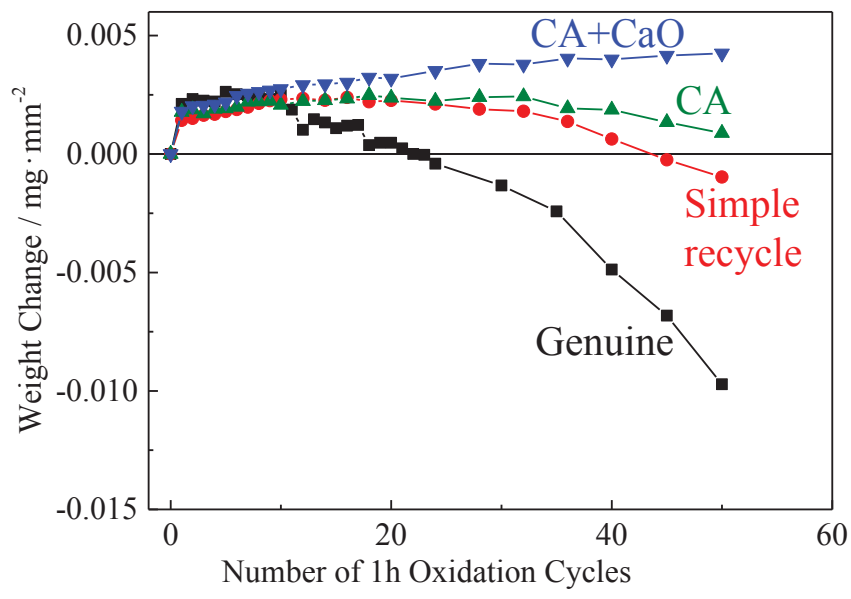

Figure 11. Weight changes of recycled material specimens obtained by cyclic oxidation test up to 50 cycles. Composition adjusted and refined material, $\mathrm{CA}+\mathrm{CaO}$, shows the best oxidation resistance in the specimens.
All recycled materials achieved better oxidation resistance compared to the genuine material. $\mathrm{CA}+\mathrm{CaO}$ has its $\mathrm{S}$ content decreased by $\mathrm{CaO}$ crucible refining and this decrease can lead to a significant oxidation resistance improvement of $\mathrm{CA}+\mathrm{CaO}$. However, taking into account that around $10 \mathrm{ppm}$ sulfur contamination induces degradation of oxidation property of the Ni-base single crystal superalloy $[9,10]$, another mechanism should have worked on the other recycled materials to explain the results.

The notable difference of the recycled materials to the genuine material is existence of $\mathrm{Y}, \mathrm{Si}$, and $\mathrm{Zr}$ contaminated from the metallic bond coating, internal deposits, and residual ceramic coating. Yttrium has ability to improve oxidation resistance of Nibase alloys by trapping $\mathrm{S}$ in form of $\mathrm{Y}-\mathrm{S}$ compounds [19]. In Figure $8, \mathrm{Y}$ and $\mathrm{S}$ are detected from the same precipitate at the same spot after the creep test. This indicates possibility that the precipitate already existed before the creep test; creep stress and high temperature environment cause the precipitate to grow large enough to be observed. If Y-S compound existed before the cyclic oxidation test, this trapping of $\mathrm{S}$ may reduce degradation effect of $\mathrm{S}$. The contamination of $\mathrm{Si}$ and $\mathrm{Zr}$ could also explain good oxidation property of the recycled materials, since there is a report that the addition of $\mathrm{Si}$ and $\mathrm{Zr}$ to alumina forming Ni-base superalloys increases adhesiveness of oxidation scale [21, 22].

To summarize, the oxidation resistance difference of each material can be explained as follows: improvement of the simple recycled material and CA material from the genuine material is due to the effect of $\mathrm{Y}$ and $\mathrm{Zr}$, and further improvement of $\mathrm{CA}+\mathrm{CaO}$ is achieved by desulfurization. Results of the simple recycled material and CA material suggest that little deviation of major element composition does not affect the oxidation resistance.

\section{High Cycle Fatigue Tests}

Figure 12 shows results of high temperature HCF tests. For comparison, experimental results obtained by Wright et al. [22], Muto et al.[23], and Furuya et al.[24], are plotted on the same figure. Both specimens of $\mathrm{CA}+\mathrm{CaO}$ material have failed after $10^{6}$ stress cycles and this clearly shows that $\mathrm{CA}+\mathrm{CaO}$ has better $\mathrm{HCF}$ life than the genuine material specimens which have failed before $10^{6}$ stress cycles. The fracture surfaces of all specimens in the vicinity of the crack initiation site are flat and perpendicular to the longitudinal axis of the specimen. This is similar to the result reported by Wright et al.[22]. The fracture surface appearances of the specimens are shown in Figure 13. The fracture initiation site of the genuine material specimens ( $\mathrm{a}$ and $\mathrm{b}$ ) and $\mathrm{CA}+\mathrm{CaO}(\mathrm{d})$ is microporosity. On the other hand, one of the fractures of $\mathrm{CA}+\mathrm{CaO}$ (c) initiated from the surface. Crack initiation from inclusions, such as ceramic top coatings, was not observed in the recycled materials.

We are currently working on the Advanced Low Carbon Technology Research and Development Program (ALCA) "Development of direct recycle method for single crystal turbine parts". Currently, the project is at the stage of $2 \mathrm{~kg}$ to $7 \mathrm{~kg}$ scale recycling. In the next stage, we will be working together with ingot makers and the final goal is to obtain recycled ingot with the same quality as the genuine ingot. The project is scheduled to expand the scale up to $2 \mathrm{t}$ ingot casting in order to verify that the method is commercially practical. 


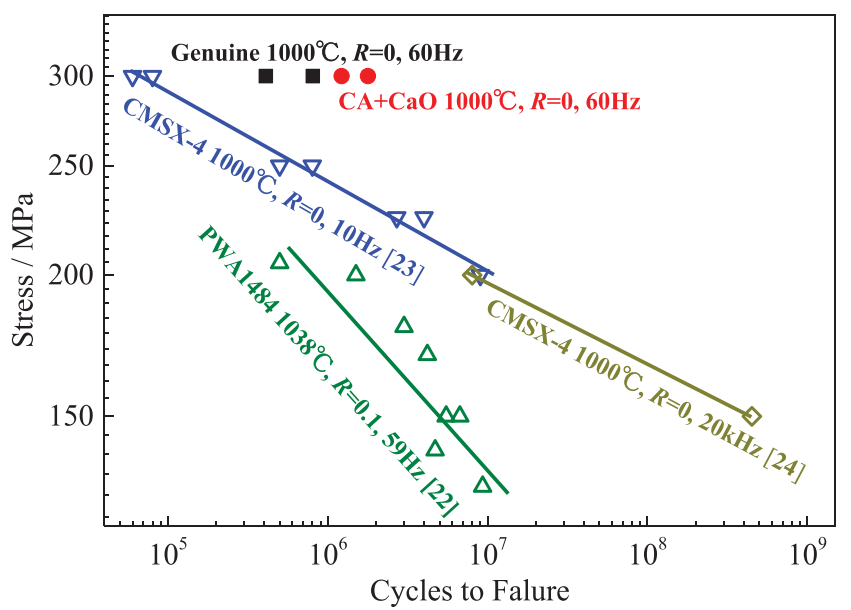

Figure 12. The results of high-temperature high cycle fatigue tests. Reference data are also shown for comparison. $\mathrm{CA}+\mathrm{CaO}$ showed longer $\mathrm{HCF}$ life than the genuine material. Internal precipitations do not affect to the HCF life of $\mathrm{CA}+\mathrm{CaO}$

\section{Conclusions}

In this study, the direct recycling of Ni-base single crystal turbine blades was performed using combination of the composition adjustment method and refining method using $\mathrm{CaO}$ crucible. The results obtained were as follows:

(1) The chemical composition of the recycled material could be controlled by Counter Alloying, i.e. the composition adjustment method. The CA method could be more effective on a commercial scale.

(2) The impurity content such as sulfur, nitrogen, and oxygen in the recycled material was successfully reduced to the same or lower level as the genuine material by the refining using a $\mathrm{CaO}$ crucible. No negative effect of other impurities is confirmed.

(3) Directly recycled material from used and scrapped turbine blades can exhibit creep strength as high as the genuine turbine blade material. Over the range of impurity contents in this study, the creep strength of the recycled material is mostly dependent on the composition of the material.

(4) The directly recycled material exhibits a better oxidation resistance than the genuine material. Desulfurization and $\mathrm{Y}$ contamination minimize the negative effects of sulfur. Also, the adhesiveness of oxidation scale is improved by $\mathrm{Si}$ and $\mathrm{Zr}$ contamination.

(5) The directly recycled material exhibits a longer HCF life than the genuine material despite having carbides form within the microstructure.

From the results above, the feasibility of the direct recycle method and application possibility of the recycled material have been clarified.



$\mathrm{CA}+\mathrm{CaO}$

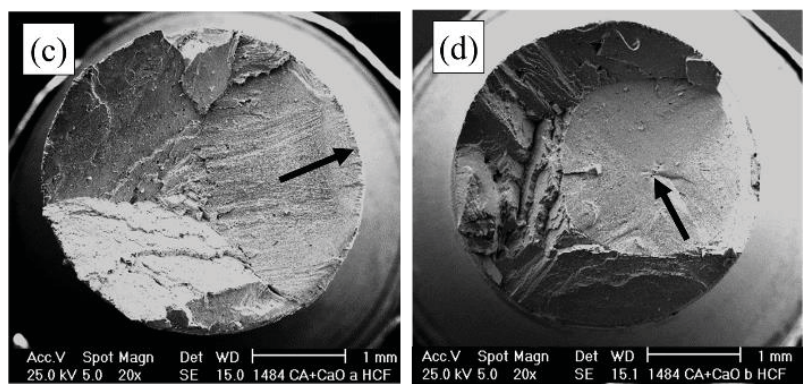

Figure 13. Fracture surfaces of HCF tests at $1000{ }^{\circ} \mathrm{C}$, stress ratio $R=0$, frequency of $60 \mathrm{~Hz}$, and stress of $300 \mathrm{MPa}$ accordance with ASTM E466. Crack initiation site for each material is marked by arrows. An internal initiation site is seen in the genuine material (a), the genuine material (b), and $\mathrm{CA}+\mathrm{CaO}(\mathrm{d})$. Only (c) shows surface crack as an initiation site.

\section{Acknowledgements}

The authors are grateful for support from Dr. S. Kawada, Dr. S. Ito, and Dr. A. Ishitoya of NIMS for chemical analyses of alloy composition. This research was supported by Japan Science and Technology Agency (JST), under Advanced Low Carbon Technology Research and Development Program (ALCA) "Development of direct recycle method for single crystal turbine parts".

\section{References}

1 H. Harada, "High Temperature Materials for Gas Turbines: the Present and Future," Proceedings of the International Gas Turbine Congress 2003 Tokyo, (2003), pp. 1-6.

2 Y. Koizumi, T. Kobayashi, T. Yokokawa, J. Zhang, M. Osawa, H. Harada, Y. Aoki, and M. Arai, "Development of Next-generation Ni-base Single Crystal Superalloys," Superalloys 2004, (Warrendale, PA: TMS, 2004), pp. 35-43.

3 S. Walston, A. Cetel, R. MacKay, K. O'Hara, D. Duhl, and R. Dreshfield, "Joint Development of a Fourth Generation Single Crystal Superalloy," Superalloys 2004, (Warrendale, PA: TMS, 2004), pp. 15-24.

4 A. Sato, H. Harada, A.-C. Yeh, K. Kawagishi, T. Kobayashi, Y. Koizumi, T. Yokokawa, and J. X. Zhang, "A 5th Generation SC Superalloy with Balanced High Temperature Properties and Processability," Superalloys 2008, (Warrendale, PA: TMS, 2008), pp. 131-138. 
5 K. Kawagishi, A. Yeh, T. Yokokawa, T. Kobayashi, Y. Koizumi, and H. Harada, "Development of an Oxidationresistant High-Strength Sixth-Generation Single-Crystal Superalloy TMS-238," Superalloys 2012, (Warrendale, PA: TMS, 2012), pp. 9-13.

6 V. Stoller, A. Olbrich, J. Meese-Marktscheffel, W. Mathy, M. Erb, G. Nietfeld, and G. Gille, U.S. Patent US20080110767 A1, "Process For Electrochemical Decomposition of Superalloys," 15-May-2008.

7 B. Palanisamy, B. Dasan, L. Ajdelsztajn, J. L. Miller, S. Sampath, and D. M. Lipkin, U.S. Patent US20110126673 A1, "Rhenium recovery from superalloys and associated methods," 2-Jun-2011.

8 T. KobayashiI, T. Yokokawa, H. Harada, Y. Koizumi, M. Sakamoto, and M. Osawa, "A Cost Effective Recycle Procedure for Ni-base Single Crystal Superalloy Components," Proceedings of 40th Annu. Conf. GTSJ, Kushiro, Japan, 2012, pp. 181-184.

9 Y. Joh, T. Kobayashi, T. Yokokawa, K. Kawagishi, M. Osawa, S. Suzuki, and H. Harada, "Effects of Sulphur on High Temperature Properties of a Ni-base Single Crystal Superalloy, TMS-1700," Proceedings of 10th Liege Conference, 2014, pp. 538-544.

10 C. Sarioglu, C. Stinner, J. Blachere, and N. Birks, "The Control of Sulfur Content in Nickel-base, Single Crystal Superalloys and its Effects on Cyclic Oxidation Resistance," Superalloys 1996, (Warrendale, PA: TMS, 1996), pp. 71-80.

11 T. Ototani, Y. Kataura, and T. Degawa, "Deoxidation of Liquid Iron and Its Alloys by Calcium Contained in Lime Crucible," Trans. Iron Steel Inst. Jpn., 16 (5) (1976). pp. 275-282.

12 S. Utada, Y. Joh, M. Osawa, T. Yokokawa, T. Kobayashi, K. Kawagishi, S. Suzuki, and H. Harada, "Direct Recycle of Used Single Crystal Superalloy Turbine Blades," Proceedings of the International Gas Turbine Congress 2015 Tokyo, 2015, pp. 1039-1043.

13 "Material Product Data Sheet Nickel Cobalt Chromium Aluminum Yttrium (NiCoCrAlY) Thermal Spray Powders," 2014. [Online]. Available: http://www.oerlikon.com/metco /en/products-services/coating-materials/coating-materialsthermal-spray/mcraly-alloys/. [Accessed: 03-Feb-2016].

14 A. D. Cetel and D. N. Duhl, "Second-Generation NickelBase Single Crystal Superalloy," Superalloys 1988, (Warrendale, PA: TMS, 1988), pp. 235-244.

15 C. Sims, N. Stoloff, and W. Hagel, Superalloys II, (New York, NY: John Wiley and Sons, 1987), pp. 97-133.

16 L. R. Liu, T. Jin, N. R. Zhao, Z. H. Wang, X. F. Sun, H. R. Guan, and Z. Q. Hu, "Effect of Carbon Additions on the Microstructure in a Ni-base Single Crystal Superalloy," Mater. Lett., 58 (17-18) (2004), pp. 2290-2294.
17 R. Darolia, D. F. Lahrman, R. D. Field, and R. Sisson, "Formation of Topologically Closed Packed Phases in Nickle Base Single Crystal Superalloys," Superalloys 1988, (Warrendale, PA: TMS, 1988), pp. 255-264.

18 H. Harada, K. Ohno, T. Yamagata, T. Yokokawa, and M. Yamazaki, "Phase Calculation and its Use in Alloy Design Program for Nickel-Base Superalloys," Superalloys 1988, (Warrendale, PA: TMS, 1988), pp. 733-742.

19 J. L. Smialek and B. A. Pint, "Optimizing Scale Adhesion on Single Crystal Superalloys," Materials Science Forum, 369-372 (I) (2004), pp. 459-466.

20 A. C. Yeh, K. Kawagishi, H. Harada, T. Yokokawa, Y. Koizumi, T. Kobayashi, D. H. Ping, J. Fujioka, and T. Suzuki, "Development of Si-bearing 4th generation Ni-base single crystal superalloys," Superalloys 2008, (Warrendale, PA: TMS, 2088) pp. 619-628.

21 A. S. Kahn, C. E. Lowell, and C. A. Barrett, "The Effect of Zirconium on the Isothermal Oxidation of Nominal Ni14Cr-24Al Alloys," J. Electrochem. Soc., 127 (3) (1980), pp. 670-679.

22 P. K. Wright, M. Jain, and D. Cameron, "High Cycle Fatigue in a Single Crystal Superalloy: Time Dependence at Elevated Temperature," Superalloys 2004, (Warrendale, PA: TMS, 2004), pp. 657-666.

23 S. Muto, M. Arai, and K. Murakami, "Fracture Surface Morphology and High-temperature Fatigue Properties of Nibase Single Crystal Alloy," Proceedings of the 27th Symposium on Fatigue, 27 (2004), pp. 181-186.

24 Y. Furuya, K. Kobayashi, M. Hayakawa, M. Sakamoto, Y. Koizumi, and H. Harada, "Development of HighTemperature Ultrasonic Fatigue Testing System," Trans. JAPAN Soc. Mech. Eng. Ser. A, 78 (789) (2012), pp. 718 727. 